\title{
Time to Antiretroviral Therapy Initiation and Its Predictors Among Newly Diagnosed HIV-Positive People in Nekemte Town, Western Ethiopia: Claim of Universal Test and Treat
}

\author{
Lami Bayisa (D) \\ Tesfaye Abera' \\ Diriba Mulisa $\mathbb{D}^{\prime}$ \\ Getu Mosisa (D) \\ Alemnesh Mosisa $\mathbb{D}^{1}$ \\ Tadesse Tolosa $\left(\mathbb{D}^{2}\right.$ \\ Ebisa Turi (iD $)^{2}$ \\ Bizuneh Wakuma (iD ${ }^{3}$ \\ Eba Abdisa $\left.{ }^{\prime}\right)^{\prime}$ \\ Diriba Bayisa $\mathbb{I}^{4}$ \\ 'Department of Nursing, Institute of \\ Health Sciences, Wollega University, \\ Nekemte, Ethiopia; ${ }^{2}$ Department of \\ Public Health, Institutes of Health \\ Sciences, Wollega University, Nekemte, \\ Ethiopia; ${ }^{3}$ Department of Pediatric \\ Nursing, Institutes of Health Sciences, \\ Wollega University, Nekemte, Ethiopia; \\ ${ }^{4}$ Department of Midwifery, Institutes of \\ Health Sciences, Wollega University, \\ Nekemte, Ethiopia
}

Background: HIV continuum of care demands early ART initiation for all HIV-infected individuals. Early ART initiation reduces onward HIV transmission facilitating rapid viral suppression. Despite this, delayed ART use is a challenge among newly diagnosed HIVpositive individuals, and there is limited evidence on time to ART initiation among this group in Ethiopia. Thus, this study aimed to assess time to ART initiation and its predictors among newly diagnosed HIV-positive individuals in Nekemte town, Western Ethiopia.

Methods: An institution-based retrospective follow-up study was conducted on 518 newly diagnosed HIV-positive people from September 5, 2016 to December 20, 2020 at Nekemte town, Western Ethiopia. Data were collected from ART intake forms, registration log books and patient charts. The collected data were entered into Epi Data version 3.1 and STATA version 14.0 was used for analysis. Survival probability was checked graphically by Kaplan-Meier curve and statistically by Log rank test. Both bivariable and multivariable Cox Proportional hazards regression models were conducted to identify the predictors of ART initiation. Hazard ratio with $95 \% \mathrm{CI}$ and p-value of $<0.05$ was used to declare a statistical significance.

Results: By the end of the follow-up, 371 (71.6\%) individuals had initiated ART with an overall incidence rate of 51.9 per 1000 [95\% CI: 54.07-66.32] person days; median time to ART initiation was 4 [IQR: 1-9] days. Being female (AHR $=1.33,95 \%$ CI: $1.06-1.67$ ), urban dwellers $(\mathrm{AHR}=2.02,95 \% \mathrm{CI}$ : 1.37-2.97), having baseline OIs (AHR $=1.62,95 \%$ CI: $1.60-4.30)$; being tested via VCT $(\mathrm{AHR}=1.33,95 \% \mathrm{CI}: 1.02-1.74)$; linked from OPD $(\mathrm{AHR}=0.64,95 \% \mathrm{CI}: 0.47-0.85)$; disclosing HIV sero-status $(\mathrm{AHR}=2.07,95 \% \mathrm{CI}: 1.17$ 3.68); and college and above education level (AHR $=1.43,95 \%$ CI: 1.00-2.0) were identified as significant predictors of early initiation of ART.

Conclusion: The proportion and incidence of ART initiation was high; a short median time to ART initiation was revealed in this study. Strictly screening OIs, encouraging HIV serostatus disclosure and voluntary HIV testing are recommended to increase early ART initiation.

Keywords: ART initiation, time to ART initiation, newly diagnosed HIV positive, Ethiopia

\section{Introduction}

Department of Nursing, Institutes of Health Sciences, Wollega University, P.O. Box: 395, Nekemte, Ethiopia Tel +25l 924318I35

Email lamisabayisa@gmail.com

\section{Background}

HIV/AIDS continues to be a public health threat. By the end of 2018, about 74.9 million people were infected and 32 million had died due to acquired immune 
deficiency syndrome (AIDS) related illness globally. ${ }^{1}$ As the United Nation program on AIDS (UNAIDS) reported, by 2019, 38 million people were living with HIV and among them 1.7 million were newly infected and thousands had died of the disease. ${ }^{2}$ With limited accessibility of care and services, Sub-Saharan African (SSA) countries including Ethiopia share the highest global burden of HIV/ AIDS. $^{2,3}$

The advancement of ART accessibility leads to people living with HIV (PLHIV) to live much longer; reduces the number of people dying of AIDS; changes HIV infection into a manageable chronic disease and reduces onward HIV transmission. ${ }^{4-6}$ Thus, to start ART use immediately after the HIV diagnosis confirmed is recommended for all HIVinfected individuals regardless of their CD4 cell count level and clinical stage as in the universal test and treat (UTT) strategy. ${ }^{4,7}$ Timely ART start among PLHIV contributes a pivotal role to handle the epidemic and it shifts the focus of care from survival to improving quality of life through adherence, retention in care and speed up of viral suppression. ${ }^{8}$ In UNAIDS' ambitious plan to see globally an HIV prevalence fewer than 200,000 and to end new HIV infection by 2030 , timely ART start is a pillar strategy because it has both treatment and prevention purpose., ${ }^{2,8}$

Ethiopia has incorporated the UTT strategy in its national policy since 2016 and the current ART guideline is adhered to and implemented accordingly. ${ }^{9}$ The country exhibits variation in burdens of HIV across geographic and population groups. ${ }^{9,10}$ The HIV continuum of care follows steps such as universal HIV test, immediate ART start, and rapid viral suppression in which the full benefit of the ART will be achieved. ${ }^{11-13}$

Previous studies reported that the time from getting tested for HIV to start of ART use in newly diagnosed HIV clients varies from as short as one day to longer than 12 months. ${ }^{14-18}$

In Ethiopia, most studies are conducted on late presentation to HIV diagnosis. ${ }^{10,19-25}$ There is limited information on how long it takes to start ART for newly diagnosed HIV-positive individuals and its predictors even though the information is essential in the era of UTT to strengthen the HIV continuum of care. The HIV continuum of care demands an immediate ART start and rapid viral suppression. However, a delay in starting ART is a great challenge among newly diagnosed HIV-positive individuals which may cost them with early mortality, high health-care costs and poor retention in care, low ART uptake and poor viral suppression, which is not only affect the health of individuals but also has impacts for households, communities, and nationwide through affecting development and economic growth. ${ }^{26-29}$ Thus, this study aimed to assess time to ART initiation and its predictors among newly diagnosed HIV-positive people at Nekemte town, Western Ethiopia.

\section{Methodology}

\section{Study Setting and Period}

This facility based retrospective follow-up study was conducted in Nekemte town, Western Ethiopia among newly diagnosed HIV-positive individuals from September 5, 2016 to December 20, 2020. Nekemte town is a capital city of East Wollega Zone which is $321 \mathrm{~km}$ away from Addis Ababa in west direction. There are four governmental health facilities found in the town; two hospitals: Nekemte Specialized hospital (NSH) and Wollega University Referral hospital (WURH) and two health centers: Cheleleki health center and Bake Jama health center. In all these health facilities comprehensive HIV care services such as conducting HIV test, counseling, initiating ART and prevention of mother to child transmission (PMTCT) program are available according to the UTT strategy. The 520 study participants were proportionally allocated to the four health facilities based on number of HIV-positive people found in each facility. All newly diagnosed HIV-positive individuals who were tested for HIV since UTT at selected health facilities were included in the study whereas individuals with incomplete data were excluded from the study. Therefore, 384 study participants from NSH, 46 from WURH, 21 from Cheleleki Health Center and 69 from Bake Jama Health Center were selected and recruited to the study according to the newly diagnosed HIV-positive patients that were found at each health facility.

\section{Eligibility Criteria}

\section{Inclusion Criteria}

All newly diagnosed HIV-positive individuals at selected health facilities, aged 15 years old and above, and who were tested for HIV from September 5, 2016 to December 20, 2020 were included in the study.

\section{Exclusion Criteria}

Individuals whose data were incomplete, such as with no record of date of HIV diagnosis and date of ART initiation, were excluded from the study. 


\section{Sample Size Estimation}

To calculate sample size for survival data, log rank method which considers power and hazard ratio (HR) of the study was used. The Log rank method considers proportional hazard assumption and adjustment of withdrawal rate wherein the value of log rank is equal with q or rate of events at the end of the study. ${ }^{30}$

To calculate probability of events and survival function at time $\left(\mathrm{S}_{1}\right) \mathrm{t}$ and $\left(\mathrm{S}_{2}\right) \mathrm{t}$, STATA version 14 was used. $\log$ rank with the command of "stpower logrank 0.5 , hratio () power $(0.8)$ wdprob $(0.1)$ ", i.e. Log rank 0.5 , withdrawal probability $10 \%$ and $\mathrm{HR}$ of different variables were taken from a previous study conducted on predictors of ART initiation among treatment naive PLHIV in Myanmar in south-east Asia. ${ }^{31}$ Finally, for this study the largest sample size was selected, which was 520 .

\section{Sampling Procedure}

Data were retrieved from medical registration logbooks, ART intake forms and HIV testing and counseling logbooks. Profiles of the newly diagnosed HIV-positive people in selected health facilities were systematically recruited using their medical registration number (MRN) as sampling frame and included into the study every eighth interval (k).

\section{Study Variables Dependent Variable}

Time to ART initiation (time in days from confirmed positive HIV diagnosis (starting point) to ART initiation or start (end point)).

\section{Independent Variables}

Socio-demographic factors: Age in years, marital status (single, married, widowed, and divorced), occupation status (unemployed, house wife, gov't employed, and private work), educational level (write and read only, primary school, secondary school, and college and above), religion (Orthodox, Protestant, Muslim, and Catholic), residence (rural, urban).

Baseline clinical and laboratory factors: Baseline CD4 cell count, WHO clinical stage, baseline OIs (Yes/No), functional status (working, ambulatory, bedridden), baseline comorbidity (Yes/No), TB screening (Yes/No), TB/ HIV co-infection (Yes/No).

Personal and family factors: Disclosure status (Yes/ No), partner HIV status (Positive/Negative/Unknown).
Structural and Regimen related factors: HIV test approach (VCT/PICT), years diagnosed for HIV (2016/ 2017/2018/2019/200), use baseline CPT (Yes/No), and use baseline IPT (Yes/No), and place of HIV diagnosis (hospital/health center).

\section{Operational Definition}

ART initiation (Event): Commencing of lifelong therapy after positive HIV diagnosis has confirmed and the first time at which newly diagnosed HIV-positive person start to collect ART.

Censored: Newly diagnosed HIV-positive people, who either died, transferred out, lost from follow-up before initiating ART, and not yet started ART when study was ended.

\section{Functional Status}

Working: Able to perform usual work in or out of the house; Ambulatory: Able to perform activities of daily living; Bedridden: Not able to perform activities of daily living. ${ }^{33}$

\section{Data Collection Tools and Quality Control}

The data were collected using a checklist which was developed from different literatures in line with HIV testing and counseling services (HTCS) logbooks and ART intake forms. The checklist contains socio-demographic data, baseline clinical data, baseline laboratory data, personal related data, family related data, and structure or regimen-related data.

To assure the quality of data, one day of intensive training was provided for data collectors and supervisors by the principal investigator on clarity of tools and data handling including confidentiality assurance. Pre-test of the tool was conducted on $5 \%$ of patient's records before the actual data collection started to check the clarity of terms in the questionnaire. Accordingly, possible modification was carried out. Eight data collectors (clinical nurse) and four supervisors (BSc Nurse) participated in data collection. Completeness and consistency of the collected data were checked by the principal investigator on a daily basis. To ensure confidentiality, data were collected anonymously and the collected data were kept in a locked cabinet to avoid its access by a third body.

\section{Data Management and Analysis}

Epi data version 3.1 was used for data entry and further analysis was performed using STATA version 14.0. Data 
were cleaned, edited, re-categorized and categorized prior to the actual analysis. Descriptive survival analysis such as life table and Kaplan-Meier function curve were computed to estimate survival probability. A day was used as time scale to calculate time to ART initiation. Person-days of observation was calculated as "date of ART started (event or censored) subtract date of positive HIV diagnosis confirmed". Probabilities of ART initiation at different time intervals and cumulative survival probabilities were checked by life table. Both bivariable and multivariable cox regression model analysis was performed to investigate potential predictors of ART initiation. In bivariable Cox regression model analysis, predictors which revealed association with outcome variables at the $p$-value of $<0.25$ were included into the final multivariable Cox regression model analysis. Multivariable Cox proportional hazard regression was fitted using stepwise backward elimination of variables. Lastly, the model was selected by using Akaike's Information criteria (AIC) that showed the smaller the value of the statistic, as best the model fit. Hazard Ratios (HR) with $95 \%$ confidence intervals was computed and statistical significance was declared at $5 \%$ level (p value $<0.05$ ). Cox proportional hazards regression model was used to determine factors associated with risk of ART initiation by controlling confounding factors. To assess model adequacy for proportional Hazard model, Proportional Hazard assumption was checked and goodness-of-fit or overall model adequacy of Proportional Hazard Model was assessed.

\section{Ethical Considerations}

Ethical clearance was obtained from Ethical Review Committee of Institute of Health Science Wollega University with Ref. 043/IHRSPD/13. Permission letters were obtained from the respective health facilities administrative bodies.

\section{Results}

From September 5, 2016 to December 20, 2020, about 3965 individuals were newly diagnosed and found to be HIV positive in Nekemte town. Out of a total of 520 proposed study participants, 518 were followed retrospectively for a median time of 13.46 days [IQR: 10.0616.86]; two participants were excluded due to lack of recorded date of HIV test. Out of the total study participants/observations (518), 147 (28.4\%) were censored.

\section{Socio-Demographic Characteristics of Study Participants}

The median age of newly diagnosed HIV positive people was 35 [IQR: 27-41] years. The majority of the study participants $(164 ; 31.66 \%)$ were found in age category of $\geq 40$ years old. More than half of the study participants were females $(285 ; 55 \%)$; the majority $(320 ; 61.80 \%)$ were married and $194(38 \%)$ respondents had attended formal education to the level of primary school. Regarding occupational status and religion of the participants; 156 (30\%) relied on private work and 239 (46.10\%) were Protestant, respectively. The majority of the respondents were urban dwellers $(447 ; 86.30 \%)$ (Table 1$)$.

\section{Baseline Clinical and Laboratory Characteristics of Study Participants}

The median CD4 cell count level of respondents was 334.5 [IQR: 176-562]; the median baseline hemoglobin level was 14.4 [IQR: 13.2-16.2] and the median BMI was 20.4 [IQR: 18.2-23.1]. The majority of respondents had CD4 cell count $<500$ cells $/ \mathrm{mm}^{3}(337 ; 65.10 \%)$ and had an undetectable viral load $(360 ; 69.5 \%)$; and the majority of respondents (404; 78\%) had hemoglobin $\geq 11 \mathrm{mg} / \mathrm{dl}$. Three-quarter s $(394 ; 76 \%)$ of respondents had stage I of WHO clinical category, and almost all $(469 ; 90.50 \%)$ presented with working functional status. Almost all respondents had no comorbidities $(510 ; 98.5 \%)$; were screened for TB (495; 95.7\%); and had no TB/HIV co-infection (476; 91.9\%). Most respondents had no OIs (477; 92\%), and the majority (313; 60.4\%) had normal BMI (Table 2).

\section{Facility and Structure Related Characteristics of Study Participants}

The majority $(369 ; 71.2 \%)$ of the respondents were tested for HIV via VCT approach; were linked to the ART clinic from OPD170 (32.8\%); were tested for HIV in 2018 (143; 27.6\%) and most of the HIV tests were performed at hospital (455; $87.8 \%$ ); the majority had used baseline CPT prophylaxis (316; 61\%) and baseline IPT prophylaxis (446; 86\%), and most of the respondents $(454 ; 87.6 \%)$ were from ART catchment area of selected health facilities (Table 3 ).

\section{Personal and Family Related Characteristics of Study Participants}

Almost all of the study participants $(498 ; 96.1 \%)$ had disclosed their HIV sero-status and in more than half 
Table I Socio-Demographic Characteristics of Newly Diagnosed HIV-Positive People in Nekemte Town, Western Ethiopia, 20I62020

\begin{tabular}{|c|c|c|c|}
\hline Variable Type & Categories & Frequency & Percentage (\%) \\
\hline \multirow[t]{6}{*}{ Age } & $15-19$ years old & 20 & 3.9 \\
\hline & 20-24 years old & 58 & 11.2 \\
\hline & $25-29$ years old & 96 & 18.5 \\
\hline & 30-34 years old & 81 & 15.6 \\
\hline & $35-39$ years old & 99 & 19.1 \\
\hline & $\geq 40$ years old & 164 & 31.7 \\
\hline \multirow[t]{2}{*}{ Sex } & Male & 233 & 45.0 \\
\hline & Female & 285 & 55.0 \\
\hline \multirow[t]{4}{*}{ Marital Status } & Single & 100 & 19.3 \\
\hline & Married & 320 & 61.8 \\
\hline & Divorced & 68 & 13.1 \\
\hline & Widowed & 30 & 5.8 \\
\hline \multirow[t]{4}{*}{ Educational Status } & Write and read only & 113 & 21.8 \\
\hline & Primary school & 194 & 37.5 \\
\hline & Secondary school & 135 & 26.0 \\
\hline & College and above & 76 & 14.7 \\
\hline \multirow[t]{5}{*}{ Occupational Status } & Unemployed & 49 & 9.5 \\
\hline & House wife & 154 & 29.7 \\
\hline & Gov't employed & 149 & 28.8 \\
\hline & Private work & 156 & 30.0 \\
\hline & Others* & Io & 2.0 \\
\hline \multirow[t]{4}{*}{ Religion } & Protestant & 239 & 46.1 \\
\hline & Orthodox & 223 & 43.1 \\
\hline & Muslim & 47 & 9.1 \\
\hline & Catholic & 9 & 1.7 \\
\hline \multirow[t]{2}{*}{ Residence } & Urban & 447 & 86.3 \\
\hline & Rural & 71 & 13.7 \\
\hline
\end{tabular}

Note: *Drivers, car servants.

$(277 ; 55.3 \%)$ the disclosure was to spouse. The majority of the respondents $(463 ; 89.4 \%)$ reported having a regular sexual partner, and about half those partners had positive HIV sero-status $(232 ; 50.2 \%)$. The majority (328; 63.3\%) of respondents reported presence of children with age less than 15 years in their home and the majority $(249 ; 76.2 \%)$ of those children's HIV sero-status was negative (Table 4).

\section{Survival Status of Newly Diagnosed HIV Positive People}

A total of 518 newly diagnosed HIV-positive people were followed for a mean time of 13.79 days [95\% CI: 10.40 17.19] with total time at risk of 7147 person-days. The minimum and maximum follow-up time observed was 1 day and 366 days, respectively. Overall, nearly threequarters $(371 ; 71.6 \%$ ) [95\% CI: 67.4-75.2] of newly diagnosed HIV positive people had initiated ART throughout the follow-up; 96 (18.5\%) [95\% CI: 15.4-22.1] were transferred out to other health facilities before ART initiation; 45 (8.7\%) [95\% CI: 6.7-11.7] individuals were lost to follow-up before starting ART and 6 (1.2\%) [95\% CI: $0.5-$ 2.6] individuals died before they initiated ART (Figure 1).

\section{ARTI_Antiretroviral Initiation}

To observe the estimate of the survival time, KaplanMeier and Nelson-Aalen Cumulative hazard estimation techniques were used. The graph of Nelson-Aalen Cumulative hazard estimations showed that an increase in the hazard rate has direct relation with the increment of time (Figure 2). The overall graph of Kaplan-Meier survivor function depicts that decrement of events over a follow-up period (Figure 3). 
Table 2 Baseline Clinical and Hematologic Related Characteristics of Newly Diagnosed HIV-Positive People in Nekemte Town, Western Ethiopia, 2016-2020

\begin{tabular}{|c|c|c|c|}
\hline Variable Type & Categories & Frequency & Percentage (\%) \\
\hline \multirow[t]{2}{*}{ Baseline CD4 cell count } & $\geq 500 \mathrm{cell} / \mathrm{mm}^{3}$ & 181 & 34.9 \\
\hline & $<500 \mathrm{cell} / \mathrm{mm}^{3}$ & 337 & 65.1 \\
\hline \multirow[t]{3}{*}{ Baseline viral load } & TND & 360 & 69.5 \\
\hline & $<1000$ copies $/ \mathrm{mL}$ & 112 & 21.6 \\
\hline & $\geq 1000$ copies $/ \mathrm{mL}$ & 46 & 8.9 \\
\hline \multirow[t]{2}{*}{ Baseline Hemoglobin } & $\geq 1 \mathrm{lmg} / \mathrm{dl}$ & 404 & 78.0 \\
\hline & $<11 \mathrm{mg} / \mathrm{dl}$ & 114 & 22.0 \\
\hline \multirow[t]{3}{*}{ Baseline WHO clinical stage } & Stage I & 394 & 76.0 \\
\hline & Stage II & 72 & 14.0 \\
\hline & Stage III/ IV & 52 & 10.0 \\
\hline \multirow[t]{3}{*}{ Functional status } & Working & 469 & 90.5 \\
\hline & Ambulatory & 32 & 6.2 \\
\hline & Bedridden & 17 & 3.3 \\
\hline \multirow[t]{2}{*}{ Comorbidities } & Yes & 8 & 1.5 \\
\hline & No & 510 & 98.5 \\
\hline \multirow[t]{2}{*}{ Baseline Ols } & Yes & 41 & 8.0 \\
\hline & No & 477 & 92.0 \\
\hline \multirow[t]{2}{*}{ Screened for TB } & Yes & 495 & 95.7 \\
\hline & No & 23 & 4.4 \\
\hline \multirow[t]{2}{*}{ HIV/TB co-infection } & Yes & 42 & 8.1 \\
\hline & No & 476 & 91.9 \\
\hline \multirow[t]{3}{*}{ BMI } & $\geq 25 \mathrm{~kg} / \mathrm{m}^{2}$ & 90 & 17.4 \\
\hline & $18-24.99 \mathrm{~kg} / \mathrm{m}^{2}$ & 313 & 60.4 \\
\hline & $\leq 17.99 \mathrm{~kg} / \mathrm{m}^{2}$ & 115 & 22.2 \\
\hline
\end{tabular}

Abbreviations: HIV/TB, human immune virus and tuberculosis co-infection; BMI, body mass index; Ols, opportunistic infections; WHO, World Health Organization; TND, target not detected; CD4, cluster of differentiation molecular 4 .

\section{Incidence and Time to ART Initiation}

The magnitude of initiated ART among newly diagnosed HIV-positive individuals by the end of follow-up was (371; 71.6\%) [95\% CI: 67.4-75.2] and the majority (264; 71.2\%) of the ART initiation occurred within 7 days of a confirmed positive HIV diagnosis. An overall incidence rate of ART initiation was 51.9 per 1000 [95\% CI: 54.07-66.32] person-days, and the median time to ART initiation (from confirmed positive HIV diagnosis to ART initiation) for newly diagnosed HIV-positive individuals was 4 [IQR: 1-9] days. The highest incidence rate of the ART initiation was observed within 7 days of enrollment to care which was $544.3 / 1000$ person-days.

\section{Predictors of ART Initiation Among Newly Diagnosed HIV-Positive People in Nekemte Town, Western Ethiopia, 2016-2020}

To identify predictors of ART initiation, bivariable Cox regression analysis was done and each independent variable was analyzed with outcome variable, and the impact of individual variable on time to ART initiation was checked before model selection. All potential predictors that had $p$-value of $\leq 0.25$ in bivariable Cox regression analysis were considered for multivariable Cox regression model analysis. Accordingly, 14 variables were selected to be included into multivariable Cox proportional hazard analysis. Then multivariable Cox proportional hazard 
Table 3 Facility and Structural Related Characteristics of Newly Diagnosed HIV-Positive People in Nekemte Town, Western Ethiopia, 2016-2020

\begin{tabular}{|c|c|c|c|}
\hline Variable Type & Categories & Frequency & Percentage (\%) \\
\hline \multirow[t]{2}{*}{ HIV test approach } & VCT & 369 & 71.2 \\
\hline & PICT & 149 & 28.8 \\
\hline \multirow[t]{5}{*}{ Linked from } & OPD & 170 & 32.8 \\
\hline & Ward & 145 & 28.0 \\
\hline & TB clinic & 72 & 14.0 \\
\hline & STI clinic & 17 & 3.2 \\
\hline & Others (ANC, PNC, MCH) & 114 & 22.0 \\
\hline \multirow[t]{5}{*}{ Years of tested for HIV } & 2016 & 79 & 15.3 \\
\hline & 2017 & 120 & 23.2 \\
\hline & 2018 & 143 & 27.6 \\
\hline & 2019 & 78 & 15.0 \\
\hline & 2020 & 98 & 18.9 \\
\hline \multirow[t]{3}{*}{ Site tested for HIV } & Hospital & 455 & 87.8 \\
\hline & Health center & 25 & 4.8 \\
\hline & Others & 38 & 7.4 \\
\hline \multirow[t]{2}{*}{ Use baseline CPT } & Yes & 316 & 61.0 \\
\hline & No & 202 & 39.0 \\
\hline \multirow[t]{2}{*}{ Use baseline IPT } & Yes & 446 & 86.0 \\
\hline & No & 72 & 14.0 \\
\hline \multirow[t]{2}{*}{ Reside within catchment area } & Yes & 454 & 87.6 \\
\hline & No & 64 & 12.4 \\
\hline
\end{tabular}

Abbreviations: TB, Tuberculosis; CPT, Cotrimoxazole Preventive Therapy; IPT, Isoniazid Preventive Therapy; HIV, Human immunodeficiency Virus; OPD, outpatient department; STI, sexually transmitted infections; ANC, antenatal care; PNC, postnatal care; $\mathrm{MCH}$, mother and child health.

analysis was performed by using backward stepwise selection, and in the multivariable Cox proportional regression analysis model seven variables (sex, residence, presence of OIs, HIV test approach, linked site, HIV disclosure status and educational level) remained significantly associated with ART initiation.

Regarding the incidence rate of ART initiation among statistically significant variables, the incidence rate of ART initiation was 115.5/1000 PD among females vs 30.8/1000 PD among males, 104.3/1000 PD among urban vs and 12.7/1000 PD among rural, 70.1/1000 PD among disclosed sero-status vs 8.5/1000 PD among not disclosed HIV serostatus, 109.1/1000 PD among VCT vs 23.4/1000 PD among PITC and 87.8/1000 PD among no OIs vs 9.2/ 1000 PD among with OIs. The difference in ART initiation rate among covariates highlights the existence of a short time from HIV test to ART initiation for covariates with high incidence rate.

Accordingly, being female, urban residence, having baseline OIs, getting tested for HIV via VCT approach, disclosing HIV sero-status and attending formal education to college and above level and linked to the ART clinic from OPD, ward, and TB clinic were independent predictors of ART initiation. Female respondents had 1.33 times higher hazard to initiate ART early compared with males $(\mathrm{AHR}=1.33,95 \%$ CI: 1.06-1.67). Individuals who came from urban areas were 2.02 times higher in initiating ART as early as possible when compared with rural dwellers $(\mathrm{AHR}=2.02,95 \%$ CI: 1.37-2.97). The hazard of initiation of ART early was 2.62 times higher in individuals with no baseline OIs when compared with their counterparts $($ AHR $=$ 1.62, 95\% CI: 1.60-4.30). Getting tested for HIV via VCT approach favors early ART initiation 1.33 times higher than that of PITC approach $($ AHR $=1.33,95 \%$ CI: 1.02-1.74). Individuals who linked to ART clinic from OPD had $36 \%$ reduction in hazard of initiating ART early $(\mathrm{AHR}=0.64,95 \% \mathrm{CI}: 0.47-0.85)$. Those who disclosed their HIV sero-status were 2.07 times more likely to initiate ART earlier when compared 
Table 4 Personal and Family Related Characteristics of Newly Diagnosed HIV-Positive People in Nekemte Town, Western Ethiopia, 2016-2020

\begin{tabular}{|l|l|l|l|}
\hline Variable Type & Categories & Frequency & Percentage (\%) \\
\hline HIV disclosure status & Disclosed & 498 & 96.1 \\
& Not disclosed & 20 & 3.9 \\
\hline To whom disclosed & Spouse & 277 & 55.3 \\
& Own child & 15 & 3.0 \\
& Parents & 179 & 35.7 \\
& Siblings & 8 & 1.6 \\
& Relatives/friends & 14 & 2.8 \\
& Others* & 8 & 1.6 \\
\hline Having partner & Yes & 463 & 89.4 \\
& No & 55 & 10.6 \\
\hline Partner's HIV status & Positive & 232 & 50.2 \\
& Negative & 216 & 46.8 \\
\hline Presence of $<15$ age children in & Unknown & 15 & 3.0 \\
\hline family & Nos & 328 & 63.3 \\
\hline HIV status of the $<15$ age & Positive & 190 & 36.7 \\
children & Negative & 53 & 16.2 \\
& Unknown & 249 & 76.2 \\
\hline
\end{tabular}

Note: *Co-workers, nearby leader.

Abbreviation: HIV, human immunodeficiency virus.

with those individuals who did not disclose their serostatus $(\mathrm{AHR}=2.07,95 \% \mathrm{CI}: 1.17-3.68)$; and respondents who attended educational level to college and above were 1.43 times more likely to initiate ART early when compared with individuals who could only write and $\mathrm{read}(\mathrm{AHR}=1.43,95 \%$ CI: $1.00-2.03)$ (Table 5).

\section{Discussion}

Rapid ART initiation is one of the strategies to increase ART uptake, engagement in care and accelerate the viral suppression. In addition, rapid ART start can potentially reduce the time during which people with newly diagnosed HIV can transmit HIV through which the epidemic will be controlled as is the UTT goal. This study was conducted to

\section{Survival Status}

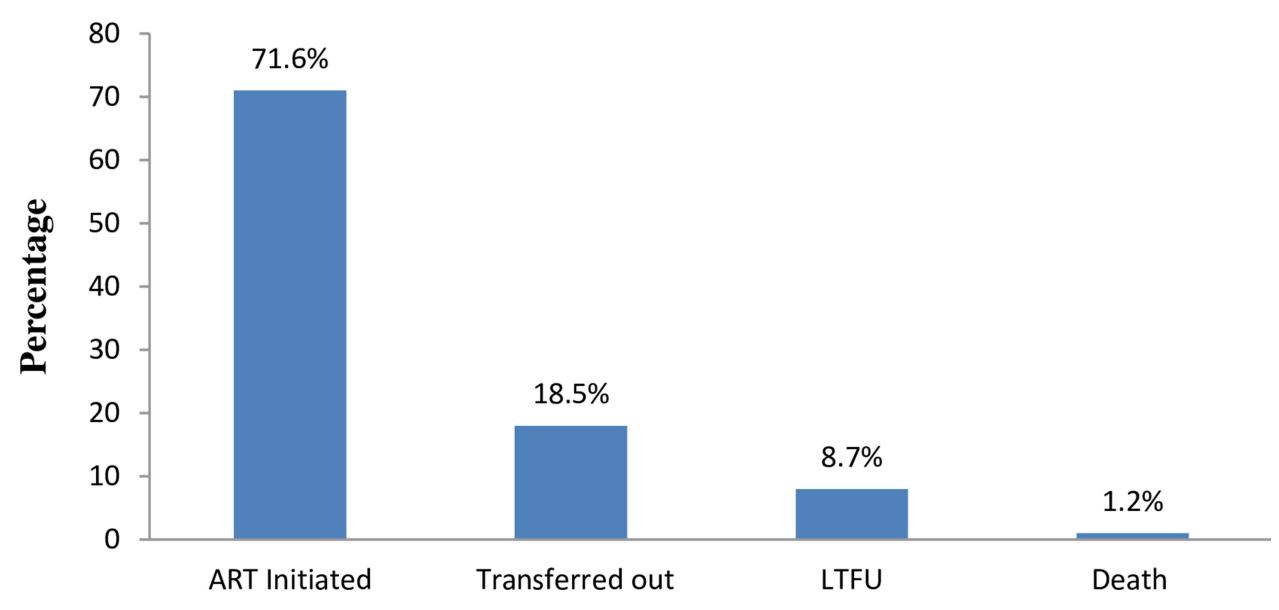

Figure I Test outcome of newly diagnosed HIV positive people in Nekemte town 2016-2020. 


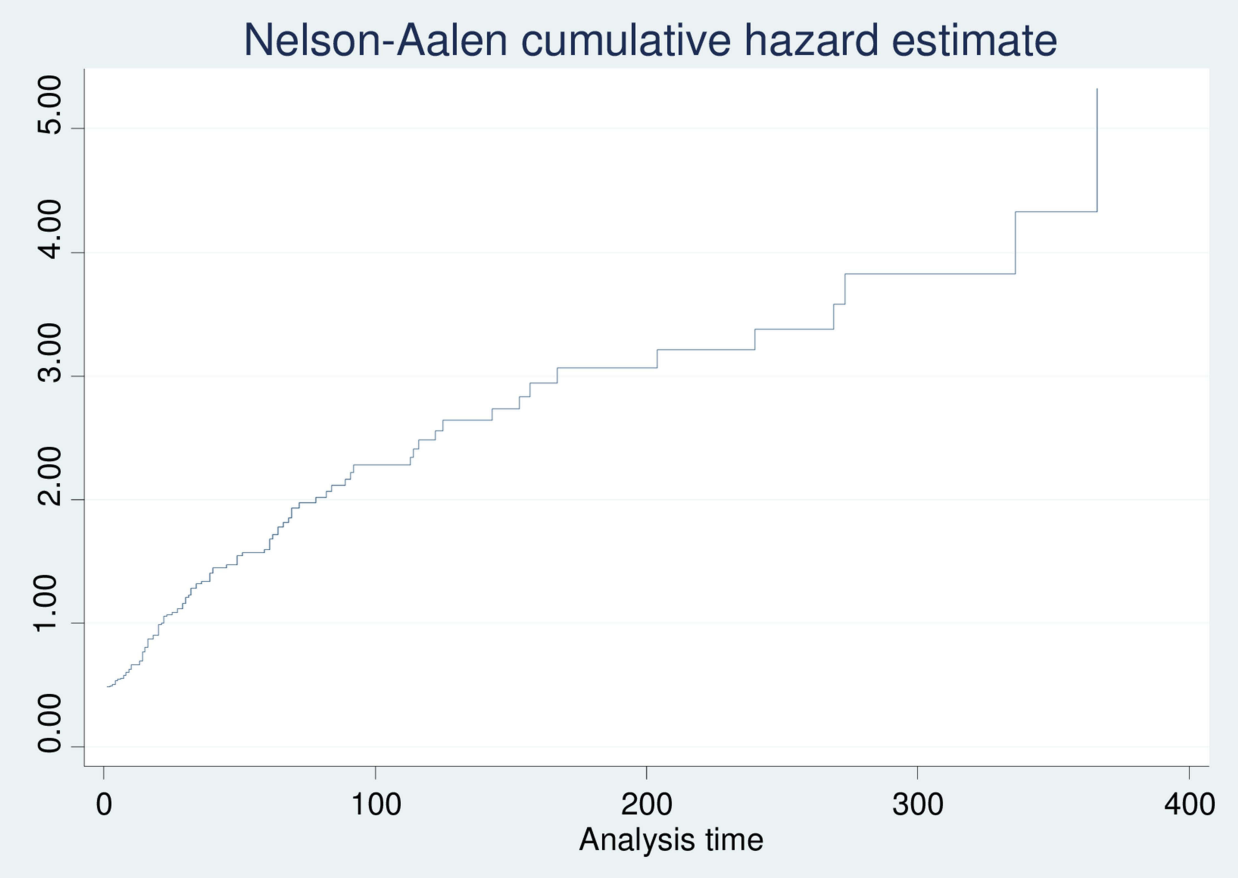

Figure 2 The Nelson-Aalen Cumulative Hazard of newly diagnosed HIV-positive people in Nekemte town from 2016-2020.

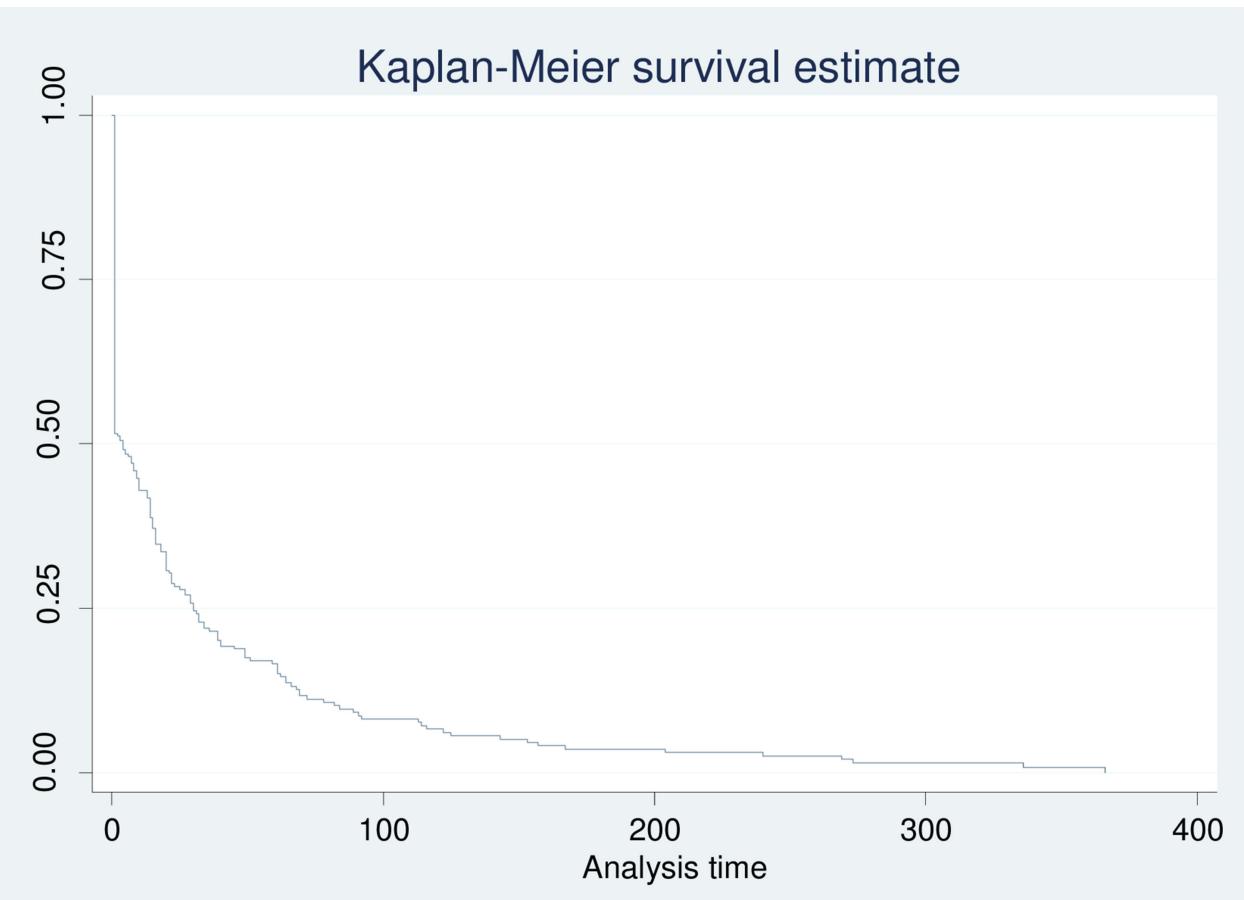

Figure 3 The overall Kaplan-Meier Survival function estimate of newly diagnosed HIV-positive people in Nekemte town from 2016-2020.

assess time to ART initiation, incidence and predictors of ART initiation among newly diagnosed HIV-positive people. Thus, the 518 study participants were recruited and followed retrospectively to assess the time to ART initiation, incidence rate of ART initiation and its predictors. At the end of follow-up, overall $71.6 \%$ of them had initiated 
Table 5 Bivariable and Multivariable Cox Proportional Hazard Model of Incidence and Predictors of ART Initiation Among Newly Diagnosed HIV-Positive People in Nekemte Town, Western Ethiopia, 2016-2020

\begin{tabular}{|c|c|c|c|c|c|c|}
\hline \multirow[t]{2}{*}{ Variables } & \multirow[t]{2}{*}{ Category } & \multicolumn{2}{|c|}{ Survival Status } & \multirow[t]{2}{*}{$\mathrm{CHR} / \mathrm{Cl}$} & \multirow[t]{2}{*}{$\mathrm{AHR} / \mathrm{Cl}$} & \multirow[t]{2}{*}{ P-value } \\
\hline & & Event & Censored & & & \\
\hline \multirow[t]{2}{*}{ Sex } & Male & 166 & 67 & I & I & 0.013 \\
\hline & Female & 205 & 80 & $1.52(1.23-1.89)$ & $1.33(1.06-1.67)$ & \\
\hline \multirow[t]{2}{*}{ Residence } & Urban & 319 & 128 & $3.05(2.14-4.36)$ & $2.02(1.37-2.97)$ & 0.001 \\
\hline & Rural & 52 & 19 & 1 & I & \\
\hline \multirow[t]{4}{*}{ WHO Clinical stage } & Stage I & 289 & 105 & 1 & 1 & \\
\hline & Stage II & 47 & 25 & $0.7(0.5 \mathrm{I}-0.97)$ & $0.84(0.60-1.16)$ & 0.302 \\
\hline & Stage III & 31 & 12 & $0.93(0.64-1.35)$ & $1.22(0.82-1.82)$ & 0.311 \\
\hline & Stage IV & 4 & 5 & $0.7(0.26-1.9)$ & $0.84(0.29-2.43)$ & 0.762 \\
\hline \multirow[t]{2}{*}{ Presence of Comorbidity } & Yes & 8 & 0 & 1 & I & 0.364 \\
\hline & No & 363 & 147 & $3.49(1.53-7.95)$ & $1.5(0.62-3.67)$ & \\
\hline \multirow[t]{2}{*}{ Presence of Ols } & Yes & 30 & 11 & 1 & I & 0.001 \\
\hline & No & 341 & 136 & $3.79(2.4 I-5.94)$ & $2.62(1.60-4.30)$ & \\
\hline \multirow[t]{2}{*}{ TB/HIV Co-infection } & Yes & 36 & 6 & 1 & 1 & 0.495 \\
\hline & No & 335 & $|4|$ & $2.13(1.44-3.14)$ & $0.85(0.55-1.33)$ & \\
\hline \multirow[t]{2}{*}{ HIV test approach } & VCT & 259 & 110 & $1.7(1.33-2.18)$ & $1.33(1.02-1.74)$ & 0.032 \\
\hline & PITC & 112 & 37 & 1 & 1 & \\
\hline \multirow[t]{5}{*}{ Linked from } & OPD & 115 & 55 & $0.7 I(0.53-0.94)$ & $0.64(0.47-0.85)$ & 0.003 \\
\hline & Ward & 101 & 44 & $0.79(0.59-1.05)$ & $0.72(0.53-0.97)$ & 0.035 \\
\hline & TB clinic & 53 & 19 & $0.73(0.52-1.03)$ & $0.69(0.48-0.99)$ & 0.049 \\
\hline & STI clinic & 11 & 6 & $0.67(0.36-1.26)$ & $0.58(0.30-1.11)$ & 0.103 \\
\hline & Others* & 91 & 23 & 1 & 1 & \\
\hline \multirow[t]{2}{*}{ Used IPT } & Yes & 341 & 105 & $1.51(1.03-2.21)$ & $1.27(0.85-1.91)$ & 0.235 \\
\hline & No & 30 & 42 & 1 & 1 & \\
\hline \multirow[t]{2}{*}{ Reside within catchment area } & Yes & 334 & 120 & I.33(0.94-1.89) & $0.97(0.66-1.44)$ & 0.906 \\
\hline & No & 37 & 27 & 1 & 1 & \\
\hline \multirow[t]{2}{*}{ HIV Disclosure status } & Disclosed & 353 & 145 & $3(1.79-5.04)$ & $2.07(1.17-3.68)$ & 0.012 \\
\hline & No Disclosed & 18 & 2 & 1 & I & \\
\hline \multirow[t]{2}{*}{ Having regular partner } & Yes & 342 & 121 & $1.54(1.03-2.28)$ & I.19(0.78-I.82) & 0.395 \\
\hline & No & 29 & 26 & 1 & 1 & \\
\hline \multirow[t]{2}{*}{ Presence of $<15$ years old children in home } & Yes & 246 & 82 & $1.49(1.19-1.87)$ & $1.09(0.86-1.820$ & 0.464 \\
\hline & No & 125 & 65 & I & 1 & \\
\hline \multirow[t]{4}{*}{ Educational level } & Write and read only & 70 & 43 & 1 & 1 & \\
\hline & Primary school & 129 & 65 & $1.03(0.77-1.38)$ & $1.04(0.77-1.4 I)$ & 0.755 \\
\hline & Secondary school & 109 & 26 & $1.25(0.89-1.64)$ & $1.25(0.9|-| .7 \mid)$ & 0.159 \\
\hline & College and above & 63 & 13 & $1.52(1.08-2.14)$ & $1.43(1.00-2.03)$ & 0.046 \\
\hline
\end{tabular}

Note: *ANC, PNC, MCH.

Abbreviations: TB, Tuberculosis; CPT, Cotrimoxazole Preventive Therapy; IPT, Isoniazid Preventive Therapy; HIV, Human immunodeficiency Virus; Ols, Opportunistic Infections; WHO, World Health Organization; CHR, Crude Hazard Ratio; AHR, Adjusted Hazard Ratio; Cl, Confidence Interval.

ART. Being female, urban dwellers, disclosing HIV serostatus, college and above educational level, having no baseline OIs, linked from OPD and getting tested for HIV via VCT approach were the predictors of early ART initiation. The overall incidence rate of ART initiation that was revealed in this study was $51.9 / 1000$ person-days observation in which $67.4 \%$ [95\% CI: 59.3-73.5] of them initiated the ART on the same day of confirmed 
positive HIV diagnosis. This result is in line with a previous study result done in Taiwan which revealed rapid ART initiation of $68.3 \%{ }^{34}$ However, this result is higher than a study result conducted in Ethiopia, ${ }^{35}$ and South Africa, ${ }^{36}$ which reported the rate of the same day ART initiation among newly diagnosed HIV positive people was $40.90 \%$ and $40.4 \%$, respectively. This inconsistency might be attributable to the study period and setting difference. The current study was conducted in multiple institutions including hospitals and health centers whereas the previous studies were done in a single institution, this might reduce the magnitude of the same day ART initiators. Additionally, the previous studies were done when the treat-all program was launched for the first time which decreases the magnitude of the same ART initiators due to lack of trained health providers on the UTT strategy, and also the patients may be more likely to refuse to accept it due to inadequate knowledge on health benefits of immediate ART initiation. Initiating ART as early as possible will positively affect the health outcome of HIVinfected individuals in that many people will be retained in care, adhere to lifelong therapy, attrition rates will be reduced and durable viral suppression will be achieved and maintained within a short period.

In this particular study, the overall median time to ART initiation was 4 [IQR: 1-9] days. This figure implies that the UTT strategy of putting all HIV-infected individuals on ART regardless of their CD4 cell count and clinical stage is applying at the study setting in a fitting way. This result is in line with study results from Kampala, Uganda that reported the median time to ART initiation was 6 days, ${ }^{8}$ and review of evidence regarding rapid ART initiation, which revealed that newly diagnosed HIV-positive individuals on average started ART within 7 days of a confirmed positive HIV diagnosis. ${ }^{37}$ However, this is shorter than in study results conducted in Myanmar, ${ }^{32}$ Croatia, $^{38}$ and Melbourne, Australia ${ }^{39}$ which reported the median time to ART initiation as of 29, 30, and 77 days respectively. The variation may be due to the different criteria used to initiate ART for newly diagnosed HIV-positive individuals. In previous studies eligibility criteria of CD4 cell count and WHO clinical stage were used to put HIVinfected individuals on ART which could take a long time. Currently, the universal test and treat strategy is working which recommends early ART initiation even including on the same day of confirmed positive HIV diagnosis, which probably shortens the median time to start ART. This finding has an implication for the proper implementation of HIV continuum of care to the study settings, which facilitates earlier viral suppression and reduces onward infection transmission. ${ }^{39}$

This study also revealed that the hazard of initiating ART as early as possible was shorter in females, urban dwellers, and individuals with baseline OIs when compared with their counterparts of male, rural dwellers, and those without baseline OIs. This finding is supported by study findings from Myanmar, South Africa, and Ekurhuleni; ${ }^{32,40,41}$ the reason why females initiated ART earlier than men may be attributed to conditions such as being pregnant, lactating and in labor and delivery, during which they are tested for HIV, and the providers strictly advise them to initiate the therapy early to prevent mother to child HIV transmission. Thus, the women may accept the advice and try to minimize the probability of infecting her neonate through placenta, labor/delivery and breast feeding and are then enforced to take ART earlier. Urban dwellers initiated ART sooner than rural dwellers. This might be due to those who were residing in urban areas being nearby to health facilities, as well as having more awareness of the health benefits of early ART initiation than those who come from rural areas. Also, urban communities have different sources of information such as television, radio, internet and then accept the orientation and advice given from health providers. The individuals from rural areas are more affected by social stigma and negative attitudes pointed towards people infected with HIV and they refuse to start ART as early as possible. The possible reason that people without baseline OIs initiated ART earlier than those individuals with baseline OIs, is that when HIV and different OIs are diagnosed at the same time, the OIs need to be treated first and the patient needs to stay on OI treatment for a specified period of time to minimize immune reconstitution inflammatory syndrome (IRIS) and then ART can be followed. It is medically recommended to delay ART initiation to some extent to stabilize patients with OIs.

For individuals who were linked to ART chronic services from OPD, Ward and TB-clinic, longer time to ART initiation was revealed than among individuals who were linked from other health units such as $\mathrm{ANC}, \mathrm{MCH}$, and delivery ward. This finding is similar with a previous study conducted in Ethiopia which revealed that pregnant women were more likely to have initiated ART on the same day of confirmed positive HIV diagnosis. ${ }^{35}$ Family planning, antenatal care and postnatal care are hospital units where the prevention of mother to child transmission 
(PMTCT) of HIV program is applied the most so far, and that is why the initiation of ART as early as the same day of confirmed positive HIV diagnosis is strictly recommended with strong follow-up and convincing approaches.

Individuals who disclosed their HIV positive sero-status more initiated ART earlier than those who did not disclose it. This might be because disclosing one's own sero-status may enable the HIV-infected individual to get economic and social support from relatives; minimize HIV-related stigma which directly or indirectly encourages the patient to commence ART as early as possible and to adhere to the lifelong therapy and medical advice. ${ }^{42,43}$ Likewise, individuals who attended educational level up to the level of college and above initiated ART earlier than those who could write and read only. Education enables people to understand the positive outcome of lifelong therapy; increases the selfconfidence to take decisions and change negative attitudes towards people living with HIV; educated people are more sociable, accept advice and direction that is provided by health providers as compared with those who are illiterate; ${ }^{44,45}$ another study result reported that among HIVinfected individuals who initiated ART, $82.8 \%$ were literate while the rest were illiterate. ${ }^{32}$ The possible explanation might be that those who are illiterate can be easily affected by HIV-related stigma; fear of being known to be HIV positive in their social circuit will outweigh the health benefits of early ART initiation and thus newly diagnosed HIVpositive illiterate individuals are put off taking ART early.

Regarding testing approaches, those who get tested for HIV through VCT initiated ART earlier than individuals who get tested via PITC approaches. This finding is supported by a previous study conducted in Ethiopia, which reported that people living with HIV who get tested through PITC were relatively delayed to initiate ART compared with those who get tested via VCT. ${ }^{46}$ Having knowledge of the impact of a late diagnosis of HIV on future health outcome and perceiving self-behavioral risks to acquire the infection may encourage people to get tested and easily start ART as early as possible if found to be positive. Individuals who get tested through VCT were more knowledgeable on risky behaviors, health outcome of early ART initiation, and how to reduce onward transmission of the infection than those who were tested via provider initiation.

\section{Limitation of the Study}

Data were retrospective follow-up in which access to full information might be difficult due to unregistered outcomes.
The true incidence of ART initiation might be overestimated or underestimated because of incomplete documentation.

\section{Conclusion}

In this study, a higher proportion and incidence rate of ART initiation was revealed, and the median time to ART initiation was shorter when compared with studies previously done in Ethiopia and other Sub-Saharan Africa countries. Being female, urban dwellers, disclosing HIV sero-status, college and above educational level, having no baseline OIs, linked from OPD and getting tested for HIV via VCT approach were the predictors of early ART initiation. Given that, the UTT strategy needs to be applied and strengthened at the study setting.

\section{Recommendation}

Strictly screening OIs before ART initiation, encouraging further HIV sero-status disclosure and disseminating health information on benefits of volunteer HIV test should be strengthened and advocated to maintain universal test and treat strategy applicability. Researchers need to conduct further research to know whether the transferredout clients were started on ART or not.

\section{Abbreviations}

HIV, human immunodeficiency virus; ART, antiretroviral therapy; CI, confidence interval; AHR, adjusted hazard ratio; OI, opportunistic infection; OPD, outpatient department; IQR, interquartile range; SSA, sub-Saharan Africa; AIDS, acquired immunodeficiency syndrome; UTT, universal test and treat; UNAIDS, United Nations program on AIDS; PLHIV, people living with HIV; NSH, Nekemte Specialized hospital; PMTCT, prevention of mother to child transmission; WURH, Wollega University referral hospital; HC, health center; MRN, medical registration number; WHO, World Health Organization; TB, tuberculosis; VCT, volunteer counsel and test; PITC, provider initiation test and counsel; IPT, isoniazid preventive therapy; CPT, cotrimoxazole preventive therapy, HTCS, HIV test and counsel services; AIC, Akaike's information criteria; TND, target not detected; PD, person-days.

\section{Data Sharing Statement}

All generated and analyzed data are included into this research article. 


\section{Ethical Approval and Consent to Participants}

Ethical approval was obtained from Institutional Review Board of Institute Health Sciences, Wollega University. Formal permission letter was obtained from each health selected facility administrative body to get the records of study participants. The patient informed consent was not taken due to the retrospective nature of data in which all information was collected from the patients' medical records. The data were collected anonymously and maintained with confidentiality. All the procedure of the data collection was conducted according to the principles of Helsinki Declaration.

\section{Acknowledgment}

We are thankful to data collectors, supervisors and health personnel for their recording of the data.

\section{Author Contributions}

All authors made a significant contribution to the work reported, whether that is in the conception, study design, execution, acquisition of data, analysis, and interpretation, or in all these areas; took part in drafting, revising or critically reviewing the articles; gave final approval of the version to be published; have agreed on the journal to which the article has been submitted; and agree to be accountable for all aspects of the work.

\section{Funding}

No funding was obtained for this research article.

\section{Disclosure}

The authors declare that they have no conflicts of interest for this work.

\section{References}

1. Global HIV \& AIDS statistics - 2019 fact sheet. Available from: https:// www.unaids.org/en/resources/fact-sheet. Accessed March 21, 2020.

2. UNAIDS, report on the global AIDS epidemic shows that 2020 targets will not be met because of deeply unequal success. COVID-19 risks blowing HIV progress way off course [Internet]; 2020 [Cited August 5, 2020]. Available from: https://www.unaids.org/en/ resources/presscentre/pressreleaseandstatementarchive/2020/july/ 20200706_global-aids-report. Accessed September 29, 2021.

3. Gesesew H, Ward P, Woldemichael K, Mwanri L. HIV care continuum outcomes: can ethiopia meet the UNAIDS 90- 90-90 Targets? Ethiop J Health Sci. 2020;30:179-188. doi:10.4314/ejhs.v30i2.5

4. Smith MK, Westreich D, Liu H, et al. Treatment to prevent HIV transmission in serodiscordant couples in Henan, China, 2006 to 2012. Clin Infect Dis. 2016;61:111-119. doi:10.1093/cid/civ200
5. Zhao Y, Wu Z, McGoogan JM, et al. Immediate antiretroviral therapy decreases mortality a nationwide, retrospective cohort study among patients with high CD4 counts in China. Clin Infect Dis. 2018;66 (5):727-734. doi:10.1093/cid/cix878

6. World Health Organization. Universal antiretroviral therapy (ART) for all HIV-infected TB patients. World Health Organization. Available from: https://www.who.int/hiv/topics/tb/art_hivpatients/en/. Accessed May 21, 2020.

7. World Health Organization. World Health Organization guideline on when to start antiretroviral therapy and on pre-exposure prophylaxis for HIV; 2015.

8. Mayanja Y, Kamacooko O, Bagiire D, Namale G, Kaleebu P, Seeley J. 'Test and treat' among women at high risk for HIVinfection in Kampala, Uganda: antiretroviral therapy initiation and associated factors. AIDS Behav. 2018;22(3):1053. doi:10.1007/ s10461-017-1973-5

9. Kibret GD, Ferede A, Leshargie CT, Wagnew F, Ketema DB, Alebel A. Trends and spatial distributions of HIV prevalence in Ethiopia. Infect Dis Poverty. 2019;8(1):90. doi:10.1186/s40249-019-0594-9

10. World Health Organization. Guidelines for managing advanced HIV disease and rapid initiation of antiretroviral therapy; 2017. Available from: http://www.ncbi.nlm.nih.gov/books/NBK475977/. Accessed August 28, 2021.

11. HIV prevention in Ethiopia national road map 2018-2020 FINAL_FINAL.pdf. Available from: https://ethiopia.unfpa.org/sites/ default/files/pub-pdf/HIV\%20Prevention\%20in\%20Ethiopia\% 20National\%20Road\%20Map\%202018\%20-\%202020\%20FINAL_ FINAL.pdf. Accessed May 29, 2020.

12. Immediate initiation of antiretroviral therapy in the outpatient clinic. Available from: http://hivinsite.ucsf.edu/InSite?page=md-ward86rapid-art. Accessed May 19, 2020.

13. Alvarez-Uria G, Pakam R, Midde M, Naik PK. Predictors of delayed antiretroviral therapy initiation, mortality, and loss to followup in HIV infected patients eligible for HIV treatment: data from an HIV cohort study in India. Biomed Res Int. 2013;2013. doi:10.1155/2013/849042

14. Benzekri NA, Sambou JF, Ndong S, et al. Prevalence, predictors, and management of advanced HIV disease among individuals initiating ART in Senegal, West Africa. BMC Infect Dis. 2019;19(1):261. doi:10.1186/s12879-019-3826-5

15. Gesesew HA, Ward P, Woldemichael K, Mwanri L. Prevalence, trend and risk factors for antiretroviral therapy discontinuation among HIVinfected adults in Ethiopia in 2003-2015. PLoS One. 2017;12(6): e0179533. doi:10.1371/journal.pone. 0179533

16. Ingabire PM, Semitala F, Kamya MR, Nakanjako D. Delayed antiretroviral therapy (ART) initiation among hospitalized adults in a resource-limited settings: a challenge to the global target of ART for $90 \%$ of HIV-infected individuals. AIDS Res Treat. 2019;2019:1-8. doi:10.1155/2019/1832152

17. Kahn TR, Desmond M, Marx GE, et al. Delayed initiation of antiretroviral therapy among HIV-discordant couples in Kenya. AIDS Care. 2013;25(3):265-272. doi:10.1080/09540121.2012.712660

18. Pacheco PR, Zara AL, Silva e Souza LC, Turchi MD. Late onset of antiretroviral therapy in adults living with HIV in an urban area in Brazil: prevalence and risk factors. J Trop Med. 2019;2019:5165313. doi:10.1155/2019/5165313

19. Boyd MA, Boffito M, Castagna A, Estrada V. Rapid initiation of antiretroviral therapy at HIV diagnosis: definition, process, knowledge gaps. HIV Med. 2019;20(S1):3-11. doi:10.1111/hiv.12708

20. Mateo-Urdiales A, Johnson S, Smith R, Nachega JB, Eshun-Wilson I. Rapid initiation of antiretroviral therapy for people living with HIV. Cochrane Database Syst Rev. 2019;2019(6). doi:10.1002/14651858. CD012962.pub2

21. Mitiku H, Abdosh T, Teklemariam Z. Factors affecting adherence to antiretroviral treatment in harari national regional state, Eastern Ethiopia. Isrn Aids. 2013;2013:960954. doi:10.1155/2013/960954 
22. Teklu AM, Delele K, Abraha M, Belayhun B, Gudina EK, Nega A. Exploratory analysis of time from HIV diagnosis to ART start, factors and effect on survival: a longitudinal follow up study at seven teaching hospitals in Ethiopia. Ethiop J Health Sci. 2017;27(1):17-28. doi:10.4314/ejhs.v27i1

23. Nash D, Tymejczyk O, Gadisa T, et al. Factors associated with initiation of antiretroviral therapy in the advanced stages of HIV infection in six Ethiopian HIV clinics, 2012 to 2013. J Int AIDS Soc. 2016;19(1):20637. doi:10.7448/IAS.19.1.20637

24. Abaynew Y, Deribew A, Deribe K. Factors associated with late presentation to HIV/AIDS care in South Wollo ZoneEthiopia: a case-control study. AIDS Res Ther. 2011;8(1):8. doi:10.1186/1742-6405-8-8

25. Tymejczyk O, Hoffman S, Kulkarni SG, et al. HIV care and treatment beliefs among patients initiating antiretroviral treatment (ART) in Oromia, Ethiopia. AIDS Behav. 2016;20(5):998-1008. doi:10.1007/ s10461-015-1184-x

26. Gesesew HA, Ward P, Woldemichael K, Mwanri L. HIV care continuum outcomes: can Ethiopia meet the UNAIDS 90- 90-90 Targets? Ethiop J Health Sci. 2020;30(2):179-188. doi:10.4314/ejhs.v30i2.5

27. Anlay DZ, Tiruneh BT. Late ART Initiation among adult HIV patients at university of Gondar Hospital, NorthWest Ethiopia. Afr Health Sci. 2019;19(3):2324-2334. doi:10.4314/ahs.v19i3

28. Assen A, Molla F, Wondimu A, et al. Late presentation for diagnosis of HIV infection among HIV positive patients in South Tigray Zone, Ethiopia. BMC Public Health. 2016;16(1):558. doi:10.1186/s12889016-3263-y

29. Bor J, Chiu C, Ahmed S, et al. Failure to initiate HIV treatment in patients with high CD 4 counts: evidence from demographic surveillance in rural South Africa. Trop Med Int Health. 2018;23 (2):206-220. doi:10.1111/tmi.13013

30. World Health Organization. Guidelines on when to start antiretroviral therapy and on pre-exposure prophylaxis for HIV; 2015.

31. Marchenko Y. Power analysis and sample-size determination in survival models with the new stpower command. Boston Univ; 2007.

32. Linn KZ, Shewade HD, Htet KKK, Maung TM, Hone S, Oo HN. Time to anti-retroviral therapy among people living with HIV enrolled into care in Myanmar: how prepared are we for 'test and treat'? Glob Health Action. 2018;11(1):1520473. doi:10.1080/ 16549716.2018.1520473

33. Thejus TJ, Jeeja MC, Jayakrishnan T. The functional status of patients with AIDS Attending antiretroviral treatment center. Indian J Palliat Care. 2009;15(1):57. doi:10.4103/0973-1075.53513

34. Huang YC, Sun HY, Chuang YC, et al. Short-term outcomes of rapid initiation of antiretroviral therapy among HIV-positive patients: real-world experience from a single-centre retrospective cohort in Taiwan. $B M J$ Open. 2019;9(9):e033246. doi:10.1136/bmjopen-2019-033246

35. Moges NA, Adesina OA, Okunlola MA, Berhane Y. Same-day antiretroviral treatment (ART) initiation and associated factors among HIV positive people in Northwest Ethiopia: baseline characteristics of prospective cohort. Arch Public Health. 2020;78(1):87. doi:10.1186/s13690-020-00473-4
36. Lilian RR, Rees K, McIntyre JA, Struthers HE, Peters RPH. Sameday antiretroviral therapy initiation for HIV-infected adults in South Africa: analysis of routine data. PLoS One. 2020;15(1):e0227572. doi:10.1371/journal.pone. 0227572

37. Michienzi SM, Barrios M, Badowski ME. Evidence regarding rapid initiation of antiretroviral therapy in patients living with HIV. Curr Infect Dis Rep. 2021;23(5):7. doi:10.1007/s11908-021-00750-5

38. Bogdanić N, Bendig L, Lukas D, Zekan Š, Begovac J. Timeliness of antiretroviral therapy initiation in the era before universal treatment. Sci Rep. 2021;11(1):10508. doi:10.1038/s41598-021-90043-7

39. Medland NA, Chow EPF, McMahon JH, Elliott JH, Hoy JF, Fairley CK. Time from HIV diagnosis to commencement of antiretroviral therapy as an indicator to supplement the HIV cascade: dramatic fall from 2011 to 2015. PLoS One. 2017;12:5. doi:10.1371/journal.pone. 0177634

40. Larsen A, Cheyip M, Tesfay A, et al. Timing and predictors of initiation on antiretroviral therapy among newly-diagnosed HIV-infected persons in South Africa. AIDS Behav. 2019;23 (2):375-385. doi:10.1007/s10461-018-2222-2

41. Mshweshwe-Pakela N, Hansoti B, Mabuto T, et al. Feasibility of implementing same-day antiretroviral therapy initiation during routine care in Ekurhuleni District, South Africa: retention and viral load suppression. South Afr J HIV Med. 2020;21(1):6. doi:10.4102/sajhivmed.v21i1.1085

42. Genet M, Sebsibie G, Gultie T. Disclosure of HIV seropositive status to sexual partners and its associated factors among patients attending antiretroviral treatment clinic follow up at Mekelle Hospital, Ethiopia: a cross-sectional study. BMC Res Notes. 2015;8:1-6. doi:10.1186/s13104-015-1056-5

43. Damian DJ, Ngahatilwa D, Fadhili H, et al. Factors associated with HIV status disclosure to partners and its outcomes among HIV-positive women attending care and treatment clinics at Kilimanjaro region, Tanzania. PLoS One. 2019;14(3):e0211921. doi:10.1371/journal.pone.0211921

44. Raberahona M, Andriananja V, Lidamahasolo Z, Andriamamonjisoa J. Knowledge, attitudes, perception and practices regarding antiretroviral therapy among HIV-infected adults in Antananarivo, Madagascar: a cross-sectional survey. BMC Health Serv Res. 2019;19:1-9. doi:10.1186/s12913-019-4173-3

45. Krakower DS, Oldenburg CE, Mitty JA, Wilson IB, Kurth AE, Maloney KM. Knowledge, beliefs and practices regarding antiretroviral medications for HIV prevention: results from a survey of healthcare providers in New England. PLoS One. 2015;10(7): e0132398. doi:10.1371/journal.pone.0132398

46. Bayisa L, Tadesse A, Reta MM, Gebeye E. Prevalence and factors associated with delayed initiation of antiretroviral therapy among people living with HIV in Nekemte Referral Hospital, Western Ethiopia. HIV/AIDS. 2020;12:457-465. doi:10.2147/HIV.S267408

\section{Publish your work in this journal}

HIV/AIDS - Research and Palliative Care is an international, peerreviewed open-access journal focusing on advances in research in HIV, its clinical progression and management options including antiviral treatment, palliative care and public healthcare policies to control viral spread. The manuscript management system is completely online and includes a very quick and fair peer-review system, which is all easy to use. Visit http://www.dovepress.com/testimonials.php to read real quotes from published authors. 